\title{
IRRESISTÍVEL VIOLÊNCIA: A REPRESENTAÇÃO DA VIOLÊNCIA NA DRAMATURGIA DO PÓS-SEGUNDA GUERRA MUNDIAL ${ }^{1}$
}

\author{
Rui Pina Coelho \\ Universidade de Lisboa
}

\section{Resumo}

A violência na sociedade e a sua representação artística têm sido desde sempre objecto de vibrantes debates. Na criação contemporânea, a violência continua a ser um dos mais insistentes refrãos temáticos motivando trabalhos que fazem confundir a realidade e a ficção, a violência e a sua representação. Este texto coloca em análise um corpus seleccionado de dramaturgia britânica de matriz realista do pós-Segunda Guerra Mundial, um período compreendido entre 1951, data de estreia da peça Saints's Day, de John Whiting, e 1967, ano de estreia de Dingo, de Charles Wood. São textos reportados a uma geração de dramaturgos que ficaram conhecidos como Angry Young Men e por uma Segunda Vaga de dramaturgos dos anos sessenta que a, seu modo, respondem às profundas alterações na geometria política e social, motivadas, em grande medida, pela Segunda Guerra Mundial. $\mathrm{Na}$ análise a que procederei, estudo a maneira como cada obra configura as representações de violência, de acordo com a seguinte tipologia: violência sistémica; violência sobre o corpo; violência verbal; e violência de guerra. Considera-se assim, a representação da violência como um meio para resgatar o teatro da banalização a que muitas vezes é sujeito e, por outro lado, demonstra-se que o teatro se revela particularmente apto a mostrála e a conceder-Ihe a gravidade necessária ao seu pleno entendimento. Do mesmo modo, revela-se a violência como um traço aglutinador e estruturante para a dramaturgia desse período e propõe-se uma aproximação a um paradigma realista que mostre ser operativo para uma interpelação a algum do teatro contemporâneo.

\section{Palavras-chave:}

Violência; Realismo; "Kitchen-Sink Drama"; Dramaturgia britânica; Pós-Segunda Guerra Mundial.

\section{Abstract}

Violence in society and its artistic portrayal have always been the subject of vigorous debates. In the contemporary arts, violence still predominates as a central theme, giving rise to works that blur the boundaries between reality and fiction, violence and its representation(s). This article analyses a selected corpus of British dramaturgy within the realist tradition, from 1951 to 1967. These are plays by the so-called Angry Young Men and by the Second Wave of playwrights in the sixties, responding ultimately to the profound transformations in political and social geometry caused by the Second World War. The plays are analysed in the light of the way that each work portrays violence accordingly to the following typologies: systemic violence, violence of the body, verbal violence and violence of war. On the one hand, violence is considered to be an efficient way to rescue theatre from the trivialisation it often suffers. On the other hand, theatre is in a particularly privileged position to show violence with all due seriousness. This study considers violence to be a fundamental feature of this period's dramaturgy and it offers an approach to a realistic paradigm that can be used to address some works of the contemporary theatre.

Keywords:

Violence; Realism; Kitchen-Sink Drama;

British Dramaturgy; Post-Second World War. 
A inquietação maior que parece ter ocupado sempre o pensamento político ocidental é a inquirição da relação entre os indivíduos e as estruturas de Poder. O século $X X$, quer nos seus dias mais solares quer nos mais soturnos, vem agudizar esta necessidade. As primeiras gerações de sociólogos e filósofos políticos fazem desta questão uma temática recorrente. Herbert Spencer, um individualista radical, critica a intervenção do Estado na vida dos cidadãos; Max Weber argumenta que a autoridade do Estado se baseia na ameaça de violência e que é o Estado quem tem o monopólio do seu uso legítimo; Georg Simmel atribui ao Estado a responsabilidade da gestão dos - inevitáveis - conflitos sociais. Mas esta é ainda a mesma questão que determinará muito do trabalho de pensadores como Benjamin, Foucault, Bourdieu, Fanon, Arendt ou Bauman, entre um vasto exército de pensadores.

Um dos aspectos centrais para a exploração deste tema é a violência existente entre as liberdades individuais e as estruturas de Poder - o que é perfeitamente compreensível uma vez que são frequentemente inconciliáveis.

Com efeito, a violência na sociedade e aquilo que me importa em particular - a sua representação artística - têm sido desde sempre objecto de vibrantes debates. Contudo, há um momento determinante para a alteração do seu paradigma: a Segunda Guerra Mundial. Com o conhecimento das atrocidades cometidas, depois do estupor e da perplexidade, a representação da violência passará a compreender a utilização da tecnologia como máquina de morte, a entender a possibilidade da destruição apocalíptica e súbita da humanidade por mão humana, a discutir a legitimidade do uso da violência e, em suma, a entender a horizontalidade, a banalidade e a omnipresença da violência.

A dramaturgia britânica deste período mostra-se particularmente apta e interessada em lidar com esta questão. $E$, em particular, a dramaturgia de matriz realista. Não que fosse mais fácil ao realismo o retrato das ruínas do pós-guerra, mas porque essa "hora do crime" desafiava, precisamente, as convenções realistas. "Não é a poesia que é impossível depois de Auschwitz, mas sim a prosa. A prosa realista falha onde a evocação poética da insuportável atmosfera dos campos [de concentração] sucede", afirma Slavoj Zizek, corrigindo Theodor Adorno. Contudo, na penosa tentativa de dar conta desse mundo, a dramaturgia realista obrigase a dirigir ao mundo um olhar impiedoso, confrontando-o directamente, tentando não contornar nem universalizar os temas tratados, revelando, assim, o seu propósito regenerador e transformador do mundo e da política.

Desta maneira, a dramaturgia britânica de matriz realista do pós-segunda guerra mundial testa a "retórica da inefabilidade" do horror e da violência e tenta compreender um mundo terrivelmente novo, encarando a representação da violência como um imperativo moral e ético, reagindo contra a progressiva banalização do mal e encarando o teatro como um acto de consequência positiva.

A esta dramaturgia (britânica de matriz realista) podemos chamar "dramaturgia de sinédoque": uma dramaturgia que, oferecendo uma parte do mundo, visava intervir no seu todo, transformando-o, denunciando as suas iniquidades e, em alguns casos, apresentando propostas de correcção e melhoramento. Uma dramaturgia que, embora partisse de motivações claramente políticas, apresentava um pensamento político confuso, assentando sobretudo em visões idiossincráticas do mundo. Uma dramaturgia que poderá ser caracterizada pelos seguintes traços: a manifestação superlativa do culto da honestidade, o que leva a uma tendência para discursos confessionais e a que muitas vezes se entendam as personagens principais como alter-egos dos seus autores; o apreço pela emoção verdadeira e pela exposição dessa emoção; a nostalgia por um passado perdido - e muitas vezes mitificado; a oposição entre aqueles que agem no plano das ideias ou intenções, e aqueles que realmente fazem; o gosto pela liberdade oferecida pelo trabalho manual; a atenção aos eventos históricos reais; a perturbadora presença de bebés, tidos muitas vezes como sinal de morte; a apresentação de fugas domésticas e privadas aos problemas do mundo; a hesitação dialética entre a adopção de uma atitude pacifista ou bélica; a manifestação de um - por vezes indistinto - sentimento de revolta; e, claro, a representação da violência. 
São textos de uma geração de dramaturgos britânicos da Primeira Vaga de realismo social, genericamente conhecidos como os "Angry Young Men" e da chamada Segunda Vaga, composta por dramaturgos dos anos sessenta. Todos eles, cada um a seu modo, respondem às profundas alterações na geometria política, cívica, social e artística, motivadas pela Segunda Guerra Mundial.

São textos que partilham igualmente uma "sensibilidade Kitchen Sink" que se traduzia numa empatia para com as dificuldades de vida da classe trabalhadora e que visava deixar um retrato suficientemente digno e objectivo do seu quotidiano para que se pudessem retirar as conclusões necessárias a uma alteração do mundo.

A representação da violência é um dos traços mais expressivos das obras deste período. E fazse de diferentes formas: representa-se a violência sobre o corpo, a violência da guerra ou a violência verbal. Mas, aquilo que melhor distingue a representação da violência neste período é a representação da violência sistémica. Esta trata da violência que é exercida sobre os indivíduos e sobre determinadas classes sociais, profissionais ou etárias, pelas instituições de Poder, pelas forças sociais dominantes, pelas circunstâncias históricas ou por quaisquer outros factores que não se exerçam através de acções de manifesta agressão. Incluem-se temas como a marginalização por razões de género, identidade sexual, etnia, classe ou proveniência geográfica, entre outros. É fácil de perceber que estas manifestações não se caracterizarão pela sua espectacularidade. Pelo contrário, traduzem comportamentos banais, institucionalizados, que, por normais, não se afiguram como uma ameaça nem como uma invasão.

Em Violence: Six Sideways Reflections, Slavoj Žižek distingue três tipos de violência. Em primeiro lugar, a violência subjectiva, "apenas a porção mais visível de um triunvirato" (Žižek 2007: 1; e dois tipos de violência objectiva: a violência simbólica, aquela que surge "corporizada na linguagem e nas suas formas"; e finalmente a violência sistémica, "ou as frequentemente catastróficas consequências do funcionamento regular dos nossos sistemas económicos e políticos" (Ibidem: 1).
Assim, quando falamos de violência sistémica falamos daquela que se exerce subtil e invisivelmente sobre os indivíduos, operada por instituições ou circunstâncias histórias, em que, aparentemente, não há um responsável visível. De acordo com Žižek, este modo de violência objectiva terá tomado uma nova forma com o capitalismo. Assim, a violência sistémica do capitalismo "não é mais atribuível a indivíduos concretos nem às suas intenções 'malévolas', mas é puramente objectiva, sistémica, anónima" (Ibidem: 11). Estas razões são tão mais prementes se entendermos que, no pósguerra, a "via capitalista" se torna bastante mais agressiva para conquistar a hegemonia no modo de vida ocidental, num debate com particulares efeitos fracturantes nas esquerdas anglo-saxónicas - matriz ideológica da quase totalidade dos dramaturgos em questão.

Dada a natureza subterrânea deste tipo de violência poder-se-ia dizer que este tipo de violência estaria presente em qualquer texto. Mas a dramaturgia britânica de matriz realista deixa um impressivo mapa de violência.

A característica mais indefectível de Saint's Day, de John Whiting, uma peça onde existem assassinatos a tiro, enforcamentos e incêndios, é a violência não nomeada que perpassa por todo o texto. Whiting trabalha a violência com um cuidado particular e em sintonia com o seu tempo. A incapacidade de explicar a natureza ou a razão das mortes provocadas pelos soldados e, em especial, a mudança de comportamento de Robert Procathren, um intelecual pacífico que se transforma num lunático sanguinário líder de uma gangue, ajuda a enfatizar o "absurdo" de toda a sociedade. Apesar de toda a violência explícita e de Saint's Dayser das peças que mais claramente interpela o clima do imediato pósguerra, a violência endémica que não chega a ser nomeada é a mais ameaçadora: e esta prende-se, essencialmente com os traumas do pós-guerra, o clima de Guerra Fria e com a engrenagem da máquina de uma sociedade de consumo capitalista.

Em Saint's Day, a acção dramática centrada sobre uma família de artistas, que se coloca à margem da sociedade, serve como pretexto para explorar uma ideia bastante intimidante: o que acontece 
se os hábitos (violentos) adquiridos durante a guerra continuarem em tempo de paz? O que impede que a violência considerada normal, aceitável, legítima, em tempo de guerra, surja de novo em tempo de paz? Portanto, Saint's Day, mais do que uma peça tematicamente alheada das questões do pós-guerra e refugiada no seu próprio labirinto referencial, é assombrada por elas: pelo medo da destruição iminente, pela violência gratuita e, muito em particular, pelo sentimento da inutilidade das artes, simbolizado no isolamento da família Southman.

Esta ideia informa vários textos - além de Saint's Day, é estruturante em Saved, de Edward Bond, onde, apesar de as personagens se envolverem nos mais hediondos actos de violência - é frequentemente citada a cena do apredejamento de um bebé -, a violência mais expressiva no texto é aquela que não é sequer nomeada - nenhuma personagem é capaz de articular as razões pelas quais vivem do modo que vivem. Ou melhor, o autor não deixa que elas as articulem, sublinhando assim, de modo mais pungente, a crise económica, social, mas também ontológica e sistémica em que todos viveriam. A indiferença que todas as personagens mostram em relação à violência circundante, à quebra dos mais elementares laços de fraternidade e solidariedade, à dissolução dos laços afectivos em permutas de interesse, tudo isto era extraordinariamente mais violento do que as cenas de violência mais explícitas. E assim se denunciava a opressão que a voraz sociedade consumista dos anos cinquenta ia impondo, e se acusava a "esquizofrenia" entre a abundância e a escassez, a ostentação e as ruínas que caracterizavam a sociedade britânica do pós-Segunda Guerra Mundial.

A mesma lógica parece habitar Afore Night Come, de David Rudkin - a violência emerge súbita e desproporcionalmente - como se os indíviduos não conseguissem mais reprimir a pressão que é exercida sobre eles. O título indicia, desde logo, essa tensão: "Six hundred bloody boxes to fill afore night come" (ANC: 29), acusa Spens. O trabalho da apanha da pêra exerce uma pressão constante sobre as personagens. Assim, o nível de violência empregue na peça de Rudkin surge inadvertidamente. Não é surpreendente que os trabalhadores sejam violentos para com Roche, o sensível estudante, mas é uma surpresa o nível de violência que aplicam, empurrando o assassinato de Roche para as áreas nebulosas do rito, tornando-se mais simbólico do que real.

Tal como em Whiting, a violência é inocentemente sádica. Se o assassinato de Roche é a cena mais impressionante da peça (esquartejado e esventrado em forma de cruz) - a verdadeira violência é aquela que se esconde detrás dos comportamentos quotidianos tidos como aceites e ordinários. Assim, a peça está cheia de referências homófobas, racistas e xenófobas. Há uma tensão permanente entre a comunidade dos trabalhadores da apanha da pêra e os recém-chegados que não é traduzida só em actos violentos, mas também em palavras e em comportamentos, aparentemente inóquos, mas que só vão perpetuando o ciclo da violência. Aquilo que Rudkin parece estar a querer propor é que sem uma ritualização colectiva da violência, através de um acto de sacrifício, esta continuará a ser aumentada até níveis intoleráveis. Mas, por outro lado, também deixa entender que para precaver a violência se devem procurar as suas raízes e actuar sobre os comportamentos sistémicos que originam, eventualmente, as explosões que são mais difíceis de controlar.

A mesma tese parece atravessar o texto de Brendan Behan, The Quare Fellow. Aparentemente, todos os reclusos reclamam uma vida normal dentro da prisão. Os crimes que os levaram ao cárcere parecem não ter importância suficiente para ser parte estruturante da narrativa. São reclusos porque, em algum momento, foram incapazes de responder à violência sistémica com normalidade e em algum momento empregaram violência de uma maneira descontrolada. Mas são reclusos também porque são o meio preciso que Brendan Behan encontrou para construir uma metáfora capaz de interpelar o mundo do pós-guerra - um mundo em que todos parecem ser reclusos, sujeitos às arbitrariedades das instituições, quer sejam as governamentais ou as policiais, ou aquelas menos visíveis, como um código moral rígido e conservador que é preciso observar e que entra em ruptura com as experiências da maior parte da população.

O sacrifício institucional, que é a execução da pena de morte aplicada ao "quare fellow", não é mais do que uma substituição dos sacríficios 
ritualistas das sociedades primitivas. Assim, nesta medida, ambos os sacrifícios parecem ser a medida exacta e necessária para que tudo possa continuar a existir e para que as comunidades visadas (os trabalhadores rurais e os reclusos) possam subsistir. Mas, em última instância, o que esta dramaturgia sugere é que, uma vez que a violência passou a fazer parte do dia-a-dia de muitos e de uma forma quase banal, há que encontrar mecanismos sociais, organizados, de expiar essa violência, caso contrário, ela aparecerá de uma forma brutal, desorganizada e indomada.

O ponto de partida de Serjeant Musgrave's Dance tem que ver precisamente com isso: com o aparecimento de uma violência de tal maneira extrema que serve de redenção a toda a restante violência (sistémica). Contudo, o ponto de partida deste texto é paradoxal: o exército, habituado às armas, vem fazer uma campanha pela paz, através de um acto radical de violência (matar vinte e cinco aldeãos como represália por cinco mortes de soldados inimigos que, por sua vez, foram represália pela morte de um outro soldado). Assim, para acabar com esta matemática de morte, propõe um sacrifício colectivo, respondendo com violência extrema à banalização da violência, ou seja, à violência sistémica. O texto de Arden, um manifesto ambíguo sobre a guerra, visa clamar pela paz, mas emprega as técnicas da guerra, enfatizando assim a brutalidade e a desumanização da sociedade. Mas Arden não se esquece de complicar esta equação, situando a acção dramática numa aldeia mineira, no momento em que os trabalhadores estão em greve. As forças políticas vão rapidamente associar-se aos soldados, pensando que estes estão ali numa missão de recrutamento. Aquilo que parece óbvio é que as instituições de poder (neste caso, governo e exército) tendem a aproximar-se e a estabelecer cumplicidades.

Mas o texto que mais directamente interpela o trauma de guerra é Dingo, de Charles Wood. Aqui, o autor dá voz ao sentimento popular de que a guerra é inútil e de que é travada por interesses que escapam aos cidadãos. Se este é um tema intemporal, convocá-lo em Inglaterra e após a Segunda Guerra Mundial é beliscar o orgulho dos vencedores e, mais relevante ainda, de todos aqueles que participaram nos combates, abrindo velhas feridas. Mas Wood fá-lo para lidar precisamente com o trauma de guerra, criando uma disforia eufórica sobre as condições reais de batalha, sublinhando - tal como Arden - a desumanização e a arbitrariedade da vida militar, ou seja, das forças sistémicas presentes nos desígnios militares (o que equivale dizer, nos interesses não nomeados das instituições de poder). O que Wood faz é "consistentemente destruir os mitos de um heroísmo infalível, protagonizados por figuras históricas como Winston Churchill" (Fowler \& Lennard 2006: 346), apresentando uma versão paródica e burlesca da guerra (Churchill aparece a urinar num acampamento militar, por exemplo). Para testar o limite da aceitação das normas sociais vigentes, Wood compõe cenas que testam os limites do realismo: o público escutará uma personagem, Chalky White, a arder até à morte num tanque de guerra; e o seu corpo carbonizado será depois trazido para cena como um boneco de ventríloquo. Assim, ultrapassar o realismo é também ultrapassar os limites impostos pela sociedade, denunciando mais eficazmente a fragilidade das condutas impostas pelas instituições de poder (neste caso em particular, o exército).

Mas o dramaturgo que de forma mais radical se tenha dirigido à acção das instituições do poder talvez seja Harold Pinter. Há, recorrentemente, nas suas primeiras peças, figuras que, de alguma maneira, são responsáveis pela manutenção das instituições. São figuras como terroristas, torturadores ou carrascos que têm que manter as exigências e as rotinas das instituições em funcionamento. Contudo, dado o frequente grau de irrazoabilidade destes critérios e exigências, estes têm frequentemente que empregar violência (e quanto menos razoáveis os critérios e exigências, mais violência será preciso empregar). Deste modo, a dramaturgia de Pinter parece estar invulgarmente preparada para interpelar um mundo do pós-Holocausto, do genocídio, da bomba nuclear e dominado pelas lógicas consumistas e individualistas.

Em The Birthday Party os torturadores / interrogadores (Goldberg e McCann) são apenas a face visível da opressão exercida sobre as personagens. As instituições, essas, em Pinter, 
ficam frequentemente anónimas. Isto reforça a dimensão de ameaça deste texto. As perguntas dos interrogadores e os actos de violência física não são em nada comparáveis com a violência muda (sistémica) exercida sobre o quotidiano de Petey e Meg, os donos da pensão, e de Stanley, que os empurra para uma existência discreta numa pequena e perdida cidade no litoral, longe do olhar de todos.

Da mesma maneira que em Whiting e Arden, em Pinter a violência aparece súbita e de forma desproporcional. Para isso muito contribui que os alicerces formais do texto sejam os do realismo, baseados em lógicas de necessidade, verosimilhança e encadeamento lógico das acções. Assim, quando a violência aparece de maneira fulgurante evidencia-se a assimetria entre as forças sistémicas operadas pelas instituições do poder e as possibilidades de reacção individual - sempre desproporcionais. Ou seja, se não atendermos às razões sistémicas que levam à emergência da violência, esta parecerá sempre surgir de forma inesperada. Mas aquilo que estes textos parecem querer provar é precisamente o contrário: que inesperado seria se, episodicamente, não houvessem explosões de violência - manifestas em todos os domínios da vida: nas relações laborais, familiares, eróticas, etc.

Se Wood e Pinter o fazem pela via da distopia, John Osborne fá-lo com cinismo e desconfiança. Em Look Back in Anger, a figura principal, Jimmy Porter, numa das passagens mais citadas, lamenta não haver mais ideais pelos quais valha a pena lutar:

There aren't any good causes left. If the big bang does come, and we all get killed off, it won't be in aid of the old-fashioned, grand design. It'll just be for the Brave new-mothing-very-muchthank-you. About as pointless and inglorious as stepping in front of a bus. ( $L B A: 83$ )

Para Porter, a Guerra Civil Espanhola terá sido a última verdadeira campanha militar e o derradeiro momento na história em que a violência seria justificada porque se batalhava por uma causa honrada. O mundo para a sua geração era um "mundo sem causas" ideológicas gregárias e mobilizadoras. Um mundo em que a rotina esmagadora do quotidiano impedia o estabelecimento de causas nobres e propósitos maiores do que a mera subsistência ou a acumulação de objectos de consumo. Esta subtracção à vida, tal como a entende a personagem, é efectuada por diversos meios: pelos jornais, pelas universidades, pela família, pelo governo. E funciona em todas as esferas, na pública como na privada. Assim, uma vez que ao indíviduo é impossível escapar à acção das instituições de poder, uma das únicas opções que terá é a fuga e a criação de refúgios privados, tal como o pequeno e singular "agregado familiar" composto por Jimmy, Alison e Cliff, que vivem juntos; ou pela brincadeira/fantasia jogada entre Jimmy e Alison, onde cada um assume o papel de um urso e de um esquilo, respectivamente, criando uma espécie de refúgio e existência alternativa ao mundo circundante.

Esta recusa de encarar o mundo aparece na dramaturgia deste período figurada de muitas formas: Stanley (BtP), Paul Southman (StD), Roche ( $A N C$ ) são todos artistas/intelectuais que se abstêem de participar na sociedade. Mas um dos exemplos mais inquietantes é o da personagem Dave - de Chicken Soup with Barley e I'm Talking about Jerusalem: de revolucionário combatente na Guerra Civil de Espanha transformar-se-á no artesão que foge às fábricas da cidade e à progressiva erosão dos laços sociais. O socialismo, para Dave, de causa universal e razão para emprestar a sua vida a um ideal maior, passará a ser uma causa privada, doméstica, extensível somente à sua família.

Mas na trilogia de Arnold Wesker a violência sistémica não se deixa entender somente pela desilusão com o socialismo de Dave. Este é - tal como já vimos - um dos traços estruturante da(s) obra(s) - mas a obra de Wesker é bem mais incisiva. Podem-se observar - como em poucas peças deste período - as forças e as movimentações sociais envolvidas num amplo processo de luta de classes. Desde as manifestações antifascistas de 1936 e da Guerra Civil de Espanha, à Segunda Guerra Mundial e à invasão da Hungria pelas tropas soviéticas, os textos vão acompanhando a maneira como a geometria política mundial vai moldando a vida, na sua dimensão mais doméstica, da família Kahn.

Com diferentes graus de resiliência, todos vão resistindo e evoluindo ao longo dos trinta anos que demora a acção dramática na trilogia. 
Mas, se em todos a desilusão e o cansaço se vai instalando, também em todos se mantém uma esperança de um optimismo militante e uma confiança no bom desenlace da luta de classes. Em todos, à excepção de Harry Kahn, a personagem mais discreta (e a menos empática) mas aquela em que mais claramente se deixam manifestar as forças sistémicas - a falência física e moral de Harry e a sua entrega ao vício e à doença traduzem bem a incapacidade dos indivíduos em fazerem face às instituições.

Por oposição, Giles Cooper, em Everything in the Garden, encontra uma maneira de colocar os indivíduos em posição de confronto com as forças sistémicas (aqui, tal como em Bond, entendidas muito claramente como as forças do capitalismo). Cooper coloca os indivíduos a circunavegarem em torno dos valores morais da classe média. Assim, para satisfazerem as necessidades de um consumismo voraz e das aparências sociais impostas pelo culto da abundância, as personagens - casais de meia idade e de classe média - entregam-se ao proxenetismo e à prostituição. São, simultaneamente, vítimas e agentes de uma violência sistémica sobre todos os indivíduos. Agem em moto próprio e livremente, mas o que fazem evidencia a ausência de soluções que os indivíduos teriam para enfrentar o mundo - pleno de violência (sistémica, tal como a entendemos aqui). Contudo, Cooper não deixa de fornecer uma espécie de justificação redentora a todo este mapa - Leonie Pimosz, a "angariadora de mulheres" para a prostituição é uma refugiada polaca sobrevivente a um campo de concentração nazi. E isso obriga a reformular toda a geometria do texto: como se os horrores da Segunda Guerra Mundial configurassem um mundo onde as leis e valores que regiam a vida colectiva tivessem deixado de fazer qualquer tipo de sentido e obrigassem à configuração de novos valores.

A representação deste tipo de violência configura um protesto e revela uma forte determinação por parte destes dramaturgos em não tomar as situações que convocam como finais e em interpelar as verdadeiras causas para a violência, assumindo-se, neste contexto, o teatro como um instrumento válido para a transformação social.

\section{CONCLUSÃO}

Em Sweet Violence: The Idea of the Tragic (2003), Terry Eagleton argumenta que na tragédia moderna o protagonista ambiciona a liberdade individual em detrimento de tudo o resto, movido por um insaciável Eros. Contudo, para garantir esta liberdade, o homem entregou as rédeas da sua segurança às instituições que regem os extremos do capitalismo tardio - e estas, perversamente, fazem associar a liberdade individual ao caos e à desordem. Assim, o herói da tragédia moderna, esmagado entre o seu desejo de liberdade e a necessidade de refúgio perante um mundo ameaçador, luta e sofre como um bode expiatório crístico que sofre os males do mundo capitalista. A dramaturgia contemporânea - desde o momento seminal que é o pós-Segunda Guerra Mundial - não tem outra alternativa a não ser dar conta do estado de guerra permanente entre Eros e as Instituições de Poder, uma guerra produtora de um sofrimento muito pouco espectacular, mas nem por isso menos real. Mas nem por isso menos violento.

\section{NOTAS}

01. Uma primeira versão deste artigo foi apresentada no Colóquio Internacional: "Teatro: Estética e Poder", na Faculdade de Letras da Universidade de Lisboa, a 22 de Novembro 2013.

\section{REFERÊNCIAS BIBLIOGRÁFICAS}

Arden, John. Serjeant Musgrave's Dance. The Methuen Book of Sixties Drama. Intro. Graham Whybrow. London: Methuen, 2001.

Behan, Brendan. The Quare Fellow. London: Eyre Methuen, 1956.

Bond, Edward, Saved. Commentary and Notes by David Davis. London: Methuen Drama, 2009.

Cooper, Giles. Everything in the Garden. Penguin Plays: New English Dramatists 7. London: Penguin, 1963, 141-221,

Fowler, Dawn and Lennard, John. "On War: Charles Wood's Military Conscience". A Companion to Modern British and Irish Drama: 
1880-2005. Ed. Mary Luckhurst. Malden / Oxford / Victoria: Blackwell Publishing, 2006, 341-357.

Osborne, John. Look Back in Anger. John Osborne: Plays One. London: Faber and Faber Limited, 1996, 1-95.

Pinter, Harold. The Birthday Party. Harold Pinter Plays: 1. London: Faber and Faber, 1991, $1-81$.

Rudkin, David. Afore Night Come. London: Young Vic Theatre Company / NT-Royal National Theatre, 2001.

Wesker, Arnold. Chicken Soup with Barley / Roots / I'm Talking about Jerusalem. Arnold Wesker: Plays I: The Wesker Trilogy. Introduced by the Author. Methuen Drama. London: Methuen, 2001.

Whiting, John. Saint's Day. John Whiting: Plays One. Edited with introductory notes by Ronald Hayman. Modern Playwrights. London: Oberon Books, 1999, 205-300.

Wood, Charles. Dingo: A Camp Concert. Charles Wood: Plays Two. London: Oberon Books, 1999, 261-375.

Žižek, Slavoj, Violence. Six Sideways Reflections. London: Profile Books, 2008.

\section{SOBRE O AUTOR}

Rui Pina Coelho (Évora, 1975) é Professor Auxiliar na Faculdade de Letras da Universidade de Lisboa e investigador no Centro de Estudos de Teatro da FLUL. Foi docente na Escola Superior de Teatro e Cinema de 2006 a 2017. Dirige a Sinais de Cena Revistade Estudos de Teatroe Artes Performativas. Publicou António Pedro (Coleção Biografias Teatro Português, CET/IN-CM/TNDMII, 2017); A hora do crime: A violência na dramaturgia britânica do pós-Segunda Guerra Mundial (1951-1967) (Peter Lang, 2016) e Casa da Comédia (1946-1975): Um palco para uma ideia de teatro (INCM, 2009), entre outros títulos. Coordena o volume Teatro Português Contemporâneo: Experimentalismo, Política e Utopia [título provisório] (Bicho do Mato/ TNDMII, 2017). Coordena o Laboratório de Escrita para Teatro, do Teatro Nacional D. Maria II. Como autor, dramaturgista ou tradutor colaborou com várias companhias. Desde 2010, colabora regularmente com o TEP - Teatro Experimental do Porto, enquanto dramaturgo e dramaturgista. 